\title{
Gas Capture Processes
}

\author{
Zhien Zhang ${ }^{1, *(\mathbb{D}}$, Tohid N. Borhani ${ }^{2}$, Muftah H. El-Naas ${ }^{3}$, Salman Masoudi Soltani ${ }^{4}$ \\ and Yunfei Yan ${ }^{5}$ \\ 1 William G. Lowrie Department of Chemical and Biomolecular Engineering, The Ohio State University, \\ Columbus, $\mathrm{OH} 43210$, USA \\ 2 School of Engineering and Physical Sciences, Heriot-Watt University, Edinburgh, Scotland EH14 4AS, UK; \\ t.nborhani@hw.ac.uk \\ 3 Gas Processing Center, College of Engineering, Qatar University, Doha 2713, Qatar; muftah@qu.edu.qa \\ 4 Department of Chemical Engineering, Brunel University London, Uxbridge UB8 3PH, UK; \\ salman.masoudisoltani@brunel.ac.uk \\ 5 Key Laboratory of Low-Grade Energy Utilization Technologies and Systems, Ministry of Education, \\ Chongqing University, Chongqing 400044, China; yunfeiyan@cqu.edu.cn \\ * Correspondence: zhang.4528@osu.edu
}

Received: 31 December 2019; Accepted: 2 January 2020; Published: 4 January 2020

\begin{abstract}
The increasing trends in gas emissions have had direct adverse impacts on human health and ecological habitats in the world. A variety of technologies have been deployed to mitigate the release of such gases, including $\mathrm{CO}_{2}, \mathrm{CO}, \mathrm{SO}_{2}, \mathrm{H}_{2} \mathrm{~S}, \mathrm{NO}_{\mathrm{x}}$ and $\mathrm{H}_{2}$. This special issue on gas-capture processes collects 25 review and research papers on the applications of novel techniques, processes, and theories in gas capture and removal.
\end{abstract}

Keywords: global warming; gas emission; capture; $\mathrm{CO}_{2}$

\section{Introduction}

The increasing trends in environmental gas emissions have had direct adverse impacts on human health and ecological habitats. Various technologies have been deployed to mitigate the release of such gases, including $\mathrm{CO}_{2}, \mathrm{CO}, \mathrm{SO}_{2}, \mathrm{H}_{2} \mathrm{~S}, \mathrm{NO}_{\mathrm{x}}$ and $\mathrm{H}_{2}$ [1-3]. Nevertheless, many of these technologies have demonstrated poor performance or are yet to become economically feasible for commercial deployment. Therefore, devising efficient capture processes and associated technologies has become significantly more urgent in the past few years.

In the current special issue of Processes, 25 review and research papers on the applications of novel techniques, processes, and theories in gas capture and removal are presented. This special issue is available online at: https://www.mdpi.com/journal/processes/special_issues/gas_capture. A concise summary of the presented works in this special issue is outlined hereafter.

\section{Overview of Papers in This Special Issue}

In the work of Mendoza et al. [4], iron ore was studied as a $\mathrm{CO}_{2}$ absorbent. Carbonation was carried out via mechanochemical and high temperature-high pressure (HTHP) reactions. Kinetics of the carbonation reactions were studied for the two methods. In the mechanochemical process, the kinetics were analyzed as a function of the $\mathrm{CO}_{2}$ pressure and the rotation speed of the planetary ball mill, while in the HTHP process, the kinetics were studied as a function of pressure and temperature. The highest $\mathrm{CO}_{2}$-capture capacities achieved were $3.7341 \mathrm{mmol}$ of $\mathrm{CO}_{2} / \mathrm{g}$ of sorbent in ball-milling ( $30 \mathrm{bar}$ of $\mathrm{CO}_{2}$ pressure, $400 \mathrm{rpm}$, and $20 \mathrm{~h}$ ) and $5.4392 \mathrm{mmol}$ of $\mathrm{CO}_{2} / \mathrm{g}$ of absorbent in HTHP (50 bar of $\mathrm{CO}_{2}$ pressure, $100{ }^{\circ} \mathrm{C}$, and $4 \mathrm{~h}$ ). To overcome the kinetic limitations, water was introduced to all carbonation experiments. The calcination reactions were carried out in an argon atmosphere using 
thermogravimetric analysis (TGA) and differential scanning calorimetry (DSC) analysis. Siderite can be decomposed in the same temperature range $\left(100^{\circ} \mathrm{C}\right.$ to $\left.420^{\circ} \mathrm{C}\right)$ as the samples produced by both methods. This range reached higher temperatures compared with pure iron oxides due to the decomposition temperature increase with decreasing purity. Calcination reactions yield magnetite and carbon. A comparison of recyclability (use of the same material in several cycles of carbonation-calcination), kinetics, spent energy, and the amounts of initial material needed to capture 1 ton of $\mathrm{CO}_{2}$ revealed the advantages of the mechanochemical process compared with HTHP.

Osagie et al. [5] conducted steady-state simulation and exergy analysis of a 2-amino-2-methyl-1 -propanol (AMP)-based post-combustion capture (PCC) plant. Exergy analysis was able to identify the location, sources of thermodynamic inefficiencies, and magnitude in the thermal system. Furthermore, thermodynamic analysis of different configurations of the process helped to identify opportunities to reduce the steam requirements for each of the configurations. Exergy analysis performed for the AMP-based plant and the different configurations revealed that a rich split with intercooling configuration gave the highest exergy efficiency of $73.6 \%$, while those of the intercooling and the reference AMP-based plant were $57.3 \%$ and $55.8 \%$, respectively. Thus, exergy analysis of flowsheeting configurations could lead to significant improvements in plant performance and to cost reduction for amine-based $\mathrm{CO}_{2}$-capture technologies.

Mahmud et al. [6] investigated the reaction kinetics of carbon dioxide with blends of $\mathrm{N}$-methyldiethanolamine and L-arginine using the stopped-flow technique. The experiments were performed over a temperature range of 293 to $313 \mathrm{~K}$, and at solution concentrations up to $1 \mathrm{~mol} / \mathrm{L}$ of different amino acid/amine ratios. The overall reaction rate constant $\left(\mathrm{k}_{\mathrm{ov}}\right)$ was found to increase with increasing temperature and amine concentration, as well as with increased proportion of L-arginine concentration in the mixture. The experimental data were fitted to the zwitterion and termolecular mechanisms using a nonlinear regression technique with average absolute deviations (AAD) of $7.6 \%$ and $8.0 \%$, respectively. A comparative study of the promoting effect of L-arginine with that of the effect of glycine and diethanolamine (DEA) in N-methyldiethanolamine (MDEA) blends showed that the MDEA-arginine blend exhibited faster reaction rate with $\mathrm{CO}_{2}$ with respect to the MDEA-DEA blend, while the case was reversed when compared to the MDEA-glycine blend.

In the study of Zhang et al. [7], four kinds of pore-forming material were screened and utilized to prepare sorbent pellets via the extrusion-spheronization process. In addition, the impacts of additional content of pore-forming material and their particle sizes were also investigated comprehensively. It was found that the addition of $5 \mathrm{wt}$. \% polyethylene resulted in the highest $\mathrm{CO}_{2}$-capture capacity ( $0.155 \mathrm{~g} \mathrm{CO}_{2} / \mathrm{g}$ sorbent in the 25 th cycle) and a mechanical performance of $4.0 \mathrm{~N}$ after high-temperature calcination, results approximately $14 \%$ higher and $25 \%$ improved, respectively, compared to pure calcium hydrate pellets. Smaller particle sizes of the pore-forming material were observed to lead to a better performance in $\mathrm{CO}_{2}$ sorption, while for mechanical performance, there was an optimal size for the pore-former used.

Gutierrez et al. [8] reported the conceptual design of an amine-based carbon dioxide $\left(\mathrm{CO}_{2}\right)$ separation process for enhanced oil recovery (EOR). A systematic approach was applied to predict the economic profitability of the system while reducing the environmental impacts. Firstly, they modeled the process with UniSim and determined the governing degrees of freedom (DoF) through a sensitivity analysis. They then proceeded with the formulation of the economic problem, where the employment of econometric models allowed them to predict the highest dynamic economic potential (DEP). In the second part of the study, the waste reduction (WAR) algorithm was applied to quantify the environmental risks of the studied process. This method was based on the minimization of the potential environmental indicator (PEI) by using the generalization of the waste reduction algorithm. Results showed that the $\mathrm{CO}_{2}$ separation plant was promising in terms of economic revenue. However, the PEI value indicated that the higher the profitability, the larger the environmental risk. The optimal value of the DEP corresponded to $0.0274 \mathrm{kmol} / \mathrm{h}$ and $60^{\circ} \mathrm{C}$, with a plant capacity according to the molar flow 
rate of the produced acid gas. In addition, the highest environmental risk was observed at the upper bounds of the DoF.

Baena-Moreno et al. [9] presented a method for regeneration of a sodium hydroxide $(\mathrm{NaOH})$ solution as a valuable byproduct from a biogas-upgrading unit through calcium carbonate $\left(\mathrm{CaCO}_{3}\right)$ precipitation, as an alternative to the elevated energy consumption required by the physical regeneration process. The purpose of this work was to study the main parameters that might affect $\mathrm{NaOH}$ regeneration using an aqueous sodium carbonate $\left(\mathrm{Na}_{2} \mathrm{CO}_{3}\right)$ solution and calcium hydroxide $\left(\mathrm{Ca}(\mathrm{OH})_{2}\right)$ as a reactive agent for regeneration and carbonate slurry production, in order to outperform the regeneration efficiencies reported in earlier works. Moreover, Raman spectroscopy and scanning electron microscopy (SEM) were employed to characterize the solid obtained. The studied parameters were reaction time, reaction temperature, and molar ratio between $\mathrm{Ca}(\mathrm{OH})_{2}$ and $\mathrm{Na}_{2} \mathrm{CO}_{3}$. In addition, the influence of small quantities of $\mathrm{NaOH}$ at the beginning of the precipitation process was studied. The results indicated that regeneration efficiencies between $53 \%$ and $97 \%$ could be obtained by varying the main parameters mentioned above, and both Raman spectroscopy and SEM images revealed the formation of a carbonate phase in the obtained solid. These results confirmed the technical feasibility of this biogas-upgrading process through $\mathrm{CaCO}_{3}$ production.

Liu et al. [10] studied the effect of physical and mechanical activation on the physicochemical structure of coal-based activated carbons (ACs). In the stage of $\mathrm{CO}_{2}$ activation, a rapid decrease of the defective structure and the growth of aromatic layers accompanied by the dehydrogenation of aromatic rings resulted in the ordered conversion of the microstructure and severe carbon losses on the surfaces of Char-PA, while the oxygen content of Char-PA, including $\mathrm{C}=\mathrm{O}(39.6 \%), \mathrm{C}-\mathrm{O}(27.3 \%), \mathrm{O}-\mathrm{C}=\mathrm{O}(18.4 \%)$, and chemisorbed $\mathrm{O}\left(\right.$ or $\left.\mathrm{H}_{2} \mathrm{O}\right)(14.7 \%)$, increased to $4.03 \%$. Char-PA presented a relatively low $\mathrm{S}_{\mathrm{BET}}$ value $\left(414.78 \mathrm{~m}^{2} / \mathrm{g}\right)$ owing to the high value of non- $V_{\text {mic }}(58.33 \%)$. In the subsequent mechanical activation from 12 to $48 \mathrm{~h}$ under $\mathrm{N}_{2}$ and dry ice, the strong mechanical collision caused by ball-milling destroyed the closely arranged crystalline layers and caused the collapse of mesopores and macropores, resulting in disordered conversion of the microstructure and the formation of a defective structure; a sustained increase in the $S_{B E T}$ value from 715.89 to $1259.74 \mathrm{~m}^{2} / \mathrm{g}$ was found with prolonged ball-milling time. There was a gradual increase in the oxygen content from $6.79 \%$ to $9.48 \%$ for Char- $\mathrm{PA}-\mathrm{CO}_{2}-12 / 48$ obtained by ball-milling under $\mathrm{CO}_{2}$. Remarkably, the variations of physicochemical parameters of Char-PA- $\mathrm{CO}_{2}-12 / 48$ were more obvious than those of Char-PA- $\mathrm{N}_{2}-12 / 48$ under the same ball-milling time, which was related to the stronger solid-gas reactions caused by the mechanical collision under dry ice. Finally, the results of the $\mathrm{SO}_{2}$ adsorption test of typical samples indicated that Char-PA- $\mathrm{CO}_{2}-48$ with a desirable physicochemical structure can maintain $100 \%$ efficiency within 30 min and its $\mathrm{SO}_{2}$ adsorption capacity could reach $138.5 \mathrm{mg} / \mathrm{g}$ at the end of the experiment. After the 10th cycle of thermal regeneration, Char-PA- $\mathrm{CO}_{2}-48$ still had a strong adsorptive capacity $(81.2 \mathrm{mg} / \mathrm{g})$.

Liu et al. [11] studied the catalytic effect of $\mathrm{NaCl}(1$ and $3 \mathrm{wt} . \%)$ in the presence of oxygen functional groups on the improvement of the physicochemical structure of coal-based activated carbons. A large quantity of $\mathrm{Na}$ can be retained in $1 \mathrm{NaJXO}$ and $3 \mathrm{NaJXO}$ with the presence of oxygen functional groups to promote further its catalytic characteristics during pyrolysis, resulting in disordered transformation of the carbon structure. In addition, the development of micropores was mainly affected by the distribution and movement of Na catalyst, whereas the growth of mesopores was mainly influenced by the evolution of oxygen functional groups. The active sites of $3 \mathrm{NaJ} \mathrm{XO}-800$ were no longer preferentially consumed in the presence of $\mathrm{Na}$ catalyst during subsequent $\mathrm{CO}_{2}$ activation to facilitate the sustained disordered conversion of the microstructure and the rapid development of the micropores, resulting in an obvious high $\mathrm{S}_{\mathrm{BET}}$ value as activation proceeded. A high $\mathrm{S}_{\mathrm{BET}}$ /burn-off ratio value $\left(41.48 \mathrm{~m}^{2} / \mathrm{g} / \%\right)$ of $3 \mathrm{NaJXO}-800$ with a high value of $\mathrm{S}_{\mathrm{BET}}\left(1995.35 \mathrm{~m}^{2} / \mathrm{g}\right)$ at a low burn-off value $(48.1 \%)$ was obtained, associated with a high efficiency of pore formation. Finally, the $\mathrm{SO}_{2}$ adsorption efficiency of 3NaJXO-800-48.1 was maintained at $100 \%$ for $90 \mathrm{~min}$. After $180 \mathrm{~min}, 3 \mathrm{NaJXO}-800-48.1$ still presented a high adsorptive capacity $(140.2 \mathrm{mg} / \mathrm{g})$. It was observed that a large micropore volume in the case of hierarchical pore structure necessarily ensured optimal adsorption of $\mathrm{SO}_{2}$. 
Karamian et al. [12] investigated the effect of different nanofluids, such as water/ $\mathrm{Al}_{2} \mathrm{O}_{3}$, water $/ \mathrm{Fe}_{2} \mathrm{O}_{3}$, or water $/ \mathrm{SiO}_{2}$, on absorption rate. The results showed that the absorption of $\mathrm{CO}_{2}$ and $\mathrm{SO}_{2}$ in nanofluids significantly increased by up to $77 \%$ in comparison with the base fluid. It was also observed that the type of gas molecules and nanoparticles determined the mechanism of mass transfer enhancement by nanofluids. Additionally, the results indicated that the values of mass transfer coefficient of $\mathrm{SO}_{2}$ in water $/ \mathrm{Al}_{2} \mathrm{O}_{3}$, water/ $/ \mathrm{Fe}_{2} \mathrm{O}_{3}$, and water $/ \mathrm{SiO}_{2}$ nanofluids were, respectively, $50 \%, 42 \%$, and $71 \%$ higher than those of $\mathrm{SO}_{2}$ in pure water $\left(\mathrm{k}_{\mathrm{LSO} 2-\text { water }}=1.45 \times 10^{-4} \mathrm{~m} / \mathrm{s}\right)$. Moreover, the values for $\mathrm{CO}_{2}$ in the above nanofluids were, respectively, $117 \%, 103 \%$, and $88 \%$ higher than those of $\mathrm{CO}_{2}$ in water alone $\left(\mathrm{k}_{\mathrm{LCO} 2-\text { water }}=1.03 \times 10^{-4} \mathrm{~m} / \mathrm{s}\right)$. Finally, this study tried to offer a new, comprehensive correlation for mass transfer coefficient and absorption rate prediction.

Petrovic and Soltani [13] optimized a post-combustion carbon-capture unit using monoethanolamine (MEA), based on a Taguchi experimental design, to understand the impacts of the operational parameters on the energy consumption of the capture unit. An equilibrium-based approach was employed in Aspen Plus to simulate 90\% capture of the $\mathrm{CO}_{2}$ emitted from a $600 \mathrm{MW}$ combined-cycle gas turbine power plant. The effects of inlet flue gas temperature, absorber column operating pressure, exhaust gas recycle ratio, and amine concentration on the energy demand were evaluated using signal-to-noise ratios and analysis of variance. The optimum parameters were found to be: flue gas temperature $=50{ }^{\circ} \mathrm{C}$, absorber pressure $=1$ bar, exhaust gas recirculation $=20 \%$, and amine concentration $=35 \mathrm{wt}$. \%, with a relative importance of amine concentration $>$ absorber column pressure $>$ exhaust gas recirculation $>$ flue gas temperature. This configuration gave a total capture unit energy requirement of $5.05 \mathrm{GJ} / \mathrm{t}_{\mathrm{CO}}$, with a reboiler energy requirement of $3.94 \mathrm{GJ} / \mathrm{t}_{\mathrm{CO} 2}$. All the studied factors, except for the flue gas temperature, demonstrated a statistically significant association to the response (i.e., energy demand).

In the study of Ge et al. [14], low-cost activated carbons were prepared from waste polyurethane foam by physical activation with $\mathrm{CO}_{2}$ and chemical activation with $\mathrm{Ca}(\mathrm{OH})_{2}, \mathrm{NaOH}$, or $\mathrm{KOH}$. The activation conditions were optimized to produce microporous carbons with high $\mathrm{CO}_{2}$ adsorption capacity and $\mathrm{CO}_{2} / \mathrm{N}_{2}$ selectivity. The sample prepared by physical activation showed $\mathrm{CO}_{2} / \mathrm{N}_{2}$ selectivity of up to 24, much higher than that of the sample prepared by chemical activation. This was mainly due to the narrower microporosity and the rich $\mathrm{N}$ content produced during the physical activation process. However, physical activation samples showed inferior textural properties compared to chemical activation samples, which led to a lower $\mathrm{CO}_{2}$ uptake of $3.37 \mathrm{mmol} / \mathrm{g}$ at $273 \mathrm{~K}$. Porous carbons obtained by chemical activation showed a high $\mathrm{CO}_{2}$ uptake of $5.85 \mathrm{mmol} / \mathrm{g}$ at $273 \mathrm{~K}$, comparable to the optimum activated carbon materials prepared from other wastes. This was mainly attributed to large volumes of ultra-micropores $(<1 \mathrm{~nm})$ up to $0.212 \mathrm{~cm}^{3} / \mathrm{g}$ and a high surface area of $1360 \mathrm{~m}^{2} / \mathrm{g}$. Furthermore, in consideration of the presence of fewer contaminants, lower weight losses of physical activation samples, and the excellent recyclability of both physically and chemically activated samples, the waste polyurethane-foam-based carbon materials have potential application prospects in $\mathrm{CO}_{2}$ capture.

Ghasem [15] studied the simultaneous absorption of $\mathrm{CO}_{2}$ and $\mathrm{NO}_{2}$ from a mixture of gases $\left(5 \% \mathrm{CO}_{2}, 300 \mathrm{ppm} \mathrm{NO}_{2}\right.$, balance $\mathrm{N}_{2}$ ) by aqueous sodium hydroxide solution in a membrane contactor. For the first time, a mathematical model was established for the simultaneous removal of the two undesired gas solutes $\left(\mathrm{CO}_{2}, \mathrm{NO}_{2}\right)$ from flue gas using a membrane contactor. The proposed model considers the reaction rate and radial and axial diffusion of both compounds. The model was verified and validated with experimental data and found to be in good agreement. The model was used to examine the effect of the flow rate of liquid, gas, and inlet solute molar fraction on the percent removal and molar flux of both impurity species. The results revealed that an increased liquid flow rate improved the percent removal of both compounds. A high inlet gas flow rate decreased the percent removal. It was possible to obtain the complete removal of both undesired compounds. The model was confirmed to be a dependable tool for the optimization of such process, and for similar systems.

Wang et al. [16] investigated the structures and electronic properties of monolayer arsenene doped with $\mathrm{Al}, \mathrm{B}, \mathrm{S}$, and $\mathrm{Si}$, based on first-principles calculations. The dopants exerted great influence on the 
properties of the arsenene monolayer. The electronic properties of the substrate were effectively tuned by substitutional doping. After doping, $\mathrm{NO}$ adsorption onto four kinds of substrate was investigated. The results demonstrated that NO exhibited a chemisorption character on Al-, B-, and Si-doped arsenene, and a physisorption character on S-doped arsenene with moderate adsorption energy. Due to the adsorption of NO, the band structures of the four systems had great changes; the adsorption reduced the energy gap of Al- and B-doped arsenene and opened the energy gap of S- and Si-doped arsenene. The large charge depletion between the NO molecule and the dopant demonstrated that there was a strong hybridization of orbitals at the surface of the doped substrate because of the formation of a covalent bond, except for S-doped arsenene. The charge depletion also indicated that Al-, B-, and Si-doped arsenene might be good candidate gas sensors to detect NO gas molecules, owing to their high sensitivity.

Shoukat et al. [17] studied various novel amine solutions both in aqueous and non-aqueous (monoethylene glycol (MEG)/triethylene glycol (TEG)) forms for hydrogen sulfide $\left(\mathrm{H}_{2} \mathrm{~S}\right)$ absorption . The study was conducted in a custom-built experimental setup at temperatures relevant to subsea operation conditions and atmospheric pressure. Liquid-phase-absorbed $\mathrm{H}_{2} \mathrm{~S}$ and amine concentrations were measured analytically to calculate $\mathrm{H}_{2} \mathrm{~S}$ loading ( $\mathrm{mol}$ of $\mathrm{H}_{2} \mathrm{~S} / \mathrm{mol}$ of amine). The maximum achieved $\mathrm{H}_{2} \mathrm{~S}$ loadings as the function of $\mathrm{pKa}$, gas partial pressure, temperature, and amine concentration were presented. The effects of solvent type on absorbed $\mathrm{H}_{2} \mathrm{~S}$ were also discussed. Several new solvents showed higher $\mathrm{H}_{2} \mathrm{~S}$ loading compared to aqueous $\mathrm{N}$-methyldiethanolamine (MDEA) solution, which is the current industrial benchmark compound for selective $\mathrm{H}_{2} \mathrm{~S}$ removal in natural gas sweetening processes.

Wang et al. [18] investigated the carbonaceous deposits on the surface of a coking chamber. Scanning electron microscopy (SEM), X-ray fluorescence spectrum (XRF), Fourier-transform infrared spectrometer (FTIR), Raman spectroscopy, X-ray diffraction spectrometry (XRD), and X-ray photoelectron spectroscopy (XPS) were applied to investigate the carbonaceous deposits. FTIR revealed the existence of carboxyl, hydroxyl, and carbonyl groups in the carbonaceous deposits. SEM showed that different carbonaceous deposit layers presented significant differences in morphology. XRF and XPS revealed that the carbonaceous deposits mainly contained $\mathrm{C}, \mathrm{O}$, and $\mathrm{N}$ elements, with smaller amounts of $\mathrm{Al}, \mathrm{Si}$, and $\mathrm{Ca}$ elements. It was found that the $\mathrm{C}$ content gradually increased in the formation of carbonaceous deposits, while the $\mathrm{O}$ and $\mathrm{N}$ elements gradually decreased. It was also found that the absorbed $\mathrm{O}_{2}$ and $\mathrm{H}_{2} \mathrm{O}$ took part in the oxidation process of the carbon skeleton to form $=\mathrm{O}$ and $-\mathrm{O}-$ structures. The oxidation and elimination reaction resulted in a change in the bonding state of the $\mathrm{O}$ element, and finally formed compact carbonaceous deposits on the surface of the coking chamber. Based on these analyses, the formation and evolution mechanisms of carbonaceous deposits were discussed.

Zhang et al. [19] proposed an oxygen recovery (OR) process for a supercritical water oxidation (SCWO) system based on the solubility difference between oxygen and $\mathrm{CO}_{2}$ in high-pressure water. A two-stage gas-liquid separation process was established, using Aspen Plus software to obtain the optimized separation parameters. Accordingly, energy consumption and economic analyses were conducted for the SCWO process with and without OR. Electricity, depreciation, and oxygen costs were the major contributions to the cost of the SCWO system without OR, accounting for 46.18, 30.24, and 18.01 $\$ / \mathrm{t}$, respectively. When OR was introduced, the total treatment cost decreased from 56.80 $\$ / \mathrm{t}$ to $46.17 \$ / \mathrm{t}$ - a reduction of $18.82 \%$. Operating costs were significantly reduced at higher values of the stoichiometric oxygen excess for the SCWO system with OR. Moreover, the treatment cost for the SCWO system with OR decreased with increasing feed concentration for increased reaction heat and oxygen recovery.

Szpalerski and Smoliński [20] presented a strategy for maximizing recovery of flare gases in industrial plants processing hydrocarbons. The functioning of a flare stack and the depressurization systems in a typical refinery plant was described, and the architecture of the depressurization systems and construction of the flares were shown in a simplified way. A proposal to recover the flare gases 
together with their output outside the industrial plant, in order to minimize impact on the environment (reduction of emissions) and to limit consumption of fossil fuels was presented. Contaminants that might be found in these depressurization systems were indicated. The proposal presented in the article assumed the injection of an excess stream of gases into an existing natural gas pipeline system. A method of monitoring was proposed, aiming to eliminate the introduction of undesirable harmful components into the systems.

Jin et al. [21] experimentally and theoretically studied the mechanism for gas transportation in emerging 2D-material-based membranes. They measured the gas permeances of hydrogen and nitrogen from their mixture through the supported MXene lamellar membrane. Knudsen diffusion and molecular sieving through straight and tortuous nanochannels were proposed to elucidate the gas transport mechanism. An average pore diameter of $5.05 \AA$ in straight nanochannels was calculated by linear regression in the Knudsen diffusion model. The activation energy for $\mathrm{H}_{2}$ transport in the molecular sieving model was calculated to be $20.54 \mathrm{~kJ} \mathrm{~mol}^{-1}$. The model indicated that the gas permeance of hydrogen (with a smaller kinetic diameter) is contributed to by both Knudsen diffusion and the molecular sieving mechanism, but the permeance of larger molecular gases like nitrogen is from Knudsen diffusion. The effects of critical conditions such as temperature, the diffusion pore diameter of structural defects, and the thickness of the prepared MXene lamellar membrane on hydrogen and nitrogen permeance were also investigated to better understand the different contributions to hydrogen permeation of Knudsen diffusion and molecular sieving. At room temperature, the total hydrogen permeance was $18 \%$ due to Knudsen diffusion and $82 \%$ due to molecular sieving. The modeling results indicated that molecular sieving plays a dominant role in controlling gas selectivity.

Zhao et al. [22] studied the influence of gas molar fraction and activity in aqueous phase while predicting phase equilibrium conditions. In pure gas systems, such as $\mathrm{CH}_{4}, \mathrm{CO}_{2}, \mathrm{~N}_{2}$ and $\mathrm{O}_{2}$, the gas molar fraction in the aqueous phase was proposed as one of phase equilibrium conditions, and a simplified correlation of the gas molar fraction was established. The gas molar fraction threshold maintaining three-phase equilibrium was obtained by phase equilibrium data regression. The UNIFAC model, the predictive Soave-Redlich-Kwong equation, and the Chen-Guo model were used to calculate aqueous phase activity and the fugacity of gas and hydrate phases, respectively. The calculations showed that the predicted phase equilibrium pressures were in good agreement with published phase equilibrium experiment data, and the percentages of absolute average deviation pressures were given. The water activity, gas molar fraction in the aqueous phase, and the fugacity coefficient in vapor phase were discussed.

Wang et al. [23] established a numerical calculation model for the rapid estimation of coal seam gas content based on the characteristic values of gas desorption at specific exposure times. Combined with technical verification, a new method which avoids the calculation of gas loss for the rapid estimation of gas content in the coal seam was investigated. Study results showed that the balanced adsorption gas pressure and coal gas desorption characteristic coefficient $\left(K_{\mathrm{t}}\right)$ satisfied the exponential equation, and the gas content and $K_{\mathrm{t}}$ were linear equations. The correlation coefficient of the fitting equation gradually decreased as the exposure time of the coal sample increased. Using the new method to measure and calculate the gas content of coal samples from two different working faces of the Lubanshan North mine (LBS), the deviation of the calculated coal sample gas content ranged from $0.32 \%$ to $8.84 \%$, with an average of only $4.49 \%$. Therefore, the new method meets the needs of field engineering technology.

In the work of Yang et al. [24], four samples with different coal ranks were collected and diffusion experiments were conducted under different pressures through the adsorption and desorption processes. Three widely used models, i.e., the unipore diffusion (UD) model, the bidisperse diffusion (BD) model, and the dispersive diffusion (DD) model, were adopted to compare their applicability and to calculate the diffusion coefficients. Results showed that for all coal ranks, the BD model and DD model could match the experimental results better than the UD model. Concerning the fast diffusion coefficient $D_{a e}$ of the BD model, three samples displayed a decreasing trend with increasing gas pressure, while the other sample showed a V-type trend. The slow diffusion coefficient $D_{i e}$ of the BD model increased with 
gas pressure for all samples, while the ratio $\beta$ is an intrinsic characteristic of coal and remained constant. For the DD model, the characteristic rate parameter $k_{\Phi}$ did not change sharply and the stretching parameter $\alpha$ increased with gas pressure. Both $D_{a e}$ and $D_{i e}$ were in proportion to $k_{\Phi}$, which reflected the diffusion rate of gas in the coal. The impacts of pore characteristic on gas diffusion were also analyzed. Although pore size distributions and specific surface areas were different between the four coal samples, correlations were not apparent between pore characteristic and diffusion coefficients.

Wang et al. [25] presented a mechanism analysis of air reactor (AR) coupling in a high-flux, coal-direct chemical looping combustion (CDCLC) system and provided a theoretical methodology for optimal system design with favorable operation stability and low gas leakages. First, they presented dipleg flow diagrams of the CDCLC system and concluded the feasible gas-solid flow states for solid circulation and gas leakage control. On this basis, semi-theoretical formulas of gas leakage were proposed to predict the optimal regions of the pressure gradients of the AR. Meanwhile, an empirical formula of critical sealing was also developed to identify the advent of circulation collapse, so as to ensure the operational stability of the whole system. Furthermore, the theoretical methodology was applied in condition design of a cold system. The resulting favorable gas-solid flow behaviors, together with the good control of gas leakages, demonstrated the feasibility of the theoretical methodology. Finally, the theoretical methodology was applied to carry out a capability assessment of a high-flux CDCLC system under a hot state in terms of the restraint of gas leakages and the stability of solid circulation.

Wang et al. [26] investigated the fundamental effects of air reactor (AR) coupling on oxygen carrier (OC) circulation and gas leakages with a cold-state experimental device of the proposed in situ gasification chemical looping combustion (iG-CLC) system. The system exhibited favorable pressure distribution characteristics and good adaptability of solid circulation flux, demonstrating the positive role of the direct coupling AR method in the stabilization and controllability of the whole system. The OC circulation and the gas leakages were mainly determined by the upper and lower pressure gradients of the AR. With an increase in the upper pressure gradient, the OC circulation flux increased initially and later decreased until the circulation collapsed. Additionally, the upper pressure gradient exerted a positive effect on the restraint of gas leakage from the FR to the AR, but a negative effect on the suppression of gas leakage from the AR to the FR. Moreover, gas leakage of the J-valve to the $\mathrm{AR}$, which is directly related to the solid circulation stability, was exacerbated with an increase of the lower pressure gradient of the AR. In real iG-CLC applications, the pressure gradients should be adjusted flexibly and optimally to guarantee balanced OC circulation together with an ideal balance of all gas leakages.

Krištof et al. [27] presented preliminary results on the spray characteristics of a spiral nozzle used for gas absorption processes. First, they experimentally measured the pressure impact footprint of the spray generated. Effective spray angles were then evaluated from the photographs of the spray and via Archimedean spiral equation using the pressure impact footprint records. Using classical photography, areas of primary and secondary atomization were determined together with the droplet size distribution, which were further approximated using selected distribution functions. Radial and tangential spray velocities of droplets were assessed using laser Doppler anemometry. The results showed atypical behavior related to different types of nozzles. In the investigated measurement range, the droplet size distribution showed higher droplet diameters (about $1 \mathrm{~mm}$ ) compared to those from, for example, air-assisted atomizers. The results were similar for the radial velocity, which was lower (a maximum velocity of about $8 \mathrm{~m} / \mathrm{s}$ ) compared to, for example, effervescent atomizers, which can produce droplets with a velocity of tens to hundreds of $\mathrm{m} / \mathrm{s}$. In contrast, the spray angle ranged from $58^{\circ}$ and $111^{\circ}$ for the inner small and large cones, respectively, to $152^{\circ}$ for the upper cone and, in the measured range, was independent of the inlet pressure of liquid at the nozzle orifice.

Ibrahim et al. [28] reviewed the main research work carried out over the last few years on direct mineral-carbonation process utilizing steel-making waste, with emphasis on recent research achievements and potential for future research. 
At the end of this editorial, the editors would like to express their sincere gratitude to the authors for their valuable contributions to this special issue and thank the editorial staff of Processes for their help and support during the review process.

\section{References}

1. Yan, J.; Zhang, Z. Carbon Capture, Utilization and Storage (CCUS). Appl. Energy 2019, 235, 1289-1299. [CrossRef]

2. Babu, P.; Linga, P.; Kumar, R.; Englezos, P. A Review of the Hydrate Based Gas Separation (HBGS) Process for Carbon Dioxide Pre-Combustion Capture. Energy 2015, 85, 261-279. [CrossRef]

3. Zhang, Z.; Li, Y.; Zhang, W.; Wang, J.; Soltanian, M.R.; Olabi, A.G. Effectiveness of Amino Acid Salt Solutions in Capturing $\mathrm{CO}_{2}$ : A Review. Renew. Sustain. Energy Rev. 2018, 98, 179-188. [CrossRef]

4. Mora Mendoza, E.Y.; Sarmiento Santos, A.; Vera López, E.; Drozd, V.; Durygin, A.; Chen, J.; Saxena, S.K. Siderite Formation by Mechanochemical and High Pressure-High Temperature Processes for $\mathrm{CO}_{2}$ Capture Using Iron Ore as the Initial Sorbent. Processes 2019, 7, 735. [CrossRef]

5. Osagie, E.; Aliyu, A.M.; Nnabuife, S.G.; Omoregbe, O.; Etim, V. Exergy Analysis and Evaluation of the Different Flowsheeting Configurations for $\mathrm{CO}_{2}$ Capture Plant Using 2-Amino-2-Methyl-1-Propanol (AMP). Processes 2019, 7, 391. [CrossRef]

6. Mahmud, N.; Benamor, A.; Nasser, M.; El-Naas, M.H.; Tontiwachwuthikul, P. Reaction Kinetics of Carbon Dioxide in Aqueous Blends of N-Methyldiethanolamine and L-Arginine Using the Stopped-Flow Technique. Processes 2019, 7, 81. [CrossRef]

7. Zhang, Z.; Pi, S.; He, D.; Qin, C.; Ran, J. Investigation of Pore-Formers to Modify Extrusion-Spheronized CaO-Based Pellets for $\mathrm{CO}_{2}$ Capture. Processes 2019, 7, 62. [CrossRef]

8. Gutierrez, J.P.; Erdmann, E.; Manca, D. Optimal Design of a Carbon Dioxide Separation Process with Market Uncertainty and Waste Reduction. Processes 2019, 7, 342. [CrossRef]

9. Baena-Moreno, F.; Rodríguez-Galán, M.; Vega, F.; Reina, T.; Vilches, L.; Navarrete, B. Regeneration of Sodium Hydroxide from a Biogas Upgrading Unit through the Synthesis of Precipitated Calcium Carbonate: An Experimental Influence Study of Reaction Parameters. Processes 2018, 6, 205. [CrossRef]

10. Liu, D.; Hao, Z.; Zhao, X.; Su, R.; Feng, W.; Li, S.; Jia, B. Effect of Physical and Mechanical Activation on the Physicochemical Structure of Coal-Based Activated Carbons for $\mathrm{SO}_{2}$ Adsorption. Processes 2019, 7, 707. [CrossRef]

11. Liu, D.; Su, R.; Hao, Z.; Zhao, X.; Jia, B.; Dong, L. Catalytic Effect of $\mathrm{NaCl}$ on the Improvement of the Physicochemical Structure of Coal-Based Activated Carbons for $\mathrm{SO}_{2}$ Adsorption. Processes 2019, 7, 338. [CrossRef]

12. Karamian, S.; Mowla, D.; Esmaeilzadeh, F. The Effect of Various Nanofluids on Absorption Intensification of $\mathrm{CO}_{2} / \mathrm{SO}_{2}$ in a Single-Bubble Column. Processes 2019, 7, 393. [CrossRef]

13. Alexanda Petrovic, B.; Masoudi Soltani, S. Optimization of Post Combustion $\mathrm{CO}_{2}$ Capture from a Combined-Cycle Gas Turbine Power Plant via Taguchi Design of Experiment. Processes 2019, 7, 364. [CrossRef]

14. Ge, C.; Lian, D.; Cui, S.; Gao, J.; Lu, J. Highly Selective $\mathrm{CO}_{2}$ Capture on Waste Polyurethane Foam-Based Activated Carbon. Processes 2019, 7, 592. [CrossRef]

15. Ghasem, N. Modeling and Simulation of the Absorption of $\mathrm{CO}_{2}$ and $\mathrm{NO}_{2}$ from a Gas Mixture in a Membrane Contactor. Processes 2019, 7, 441. [CrossRef]

16. Wang, K.; Li, J.; Huang, Y.; Lian, M.; Chen, D. Adsorption of NO Gas Molecules on Monolayer Arsenene Doped with Al, B, S and Si: A First-Principles Study. Processes 2019, 7, 538. [CrossRef]

17. Shoukat, U.; Pinto, D.D.D.; Knuutila, H.K. Study of Various Aqueous and Non-Aqueous Amine Blends for Hydrogen Sulfide Removal from Natural Gas. Processes 2019, 7, 160. [CrossRef]

18. Wang, H.; Jin, B.; Wang, X.; Tang, G. Formation and Evolution Mechanism for Carbonaceous Deposits on the Surface of a Coking Chamber. Processes 2019, 7, 508. [CrossRef]

19. Zhang, F.; Chen, J.; Su, C.; Ma, C. Energy Consumption and Economic Analyses of a Supercritical Water Oxidation System with Oxygen Recovery. Processes 2018, 6, 224. [CrossRef] 
20. Szpalerski, J.; Smoliński, A. Analysis of the Excess Hydrocarbon Gases Output from Refinery Plants. Processes 2019, 7, 253. [CrossRef]

21. Jin, Y.; Fan, Y.; Meng, X.; Zhang, W.; Meng, B.; Yang, N.; Liu, S. Theoretical and Experimental Insights into the Mechanism for Gas Separation through Nanochannels in 2D Laminar MXene Membranes. Processes 2019, 7, 751. [CrossRef]

22. Zhao, W.; Wu, H.; Wen, J.; Guo, X.; Zhang, Y.; Wang, R. Simulation Study on the Influence of Gas Mole Fraction and Aqueous Activity under Phase Equilibrium. Processes 2019, 7, 58. [CrossRef]

23. Wang, F.; Zhao, X.; Liang, Y.; Li, X.; Chen, Y. Calculation Model and Rapid Estimation Method for Coal Seam Gas Content. Processes 2018, 6, 223. [CrossRef]

24. Yang, X.; Wang, G.; Zhang, J.; Ren, T. The Influence of Sorption Pressure on Gas Diffusion in Coal Particles: An Experimental Study. Processes 2019, 7, 219. [CrossRef]

25. Wang, X.; Liu, X.; Jin, Z.; Zhu, J.; Jin, B. Theoretical Methodology of a High-Flux Coal-Direct Chemical Looping Combustion System. Processes 2018, 6, 251. [CrossRef]

26. Wang, X.; Liu, X.; Jin, B.; Wang, D. Hydrodynamic Study of AR Coupling Effects on Solid Circulation and Gas Leakages in a High-Flux In Situ Gasification Chemical Looping Combustion System. Processes 2018, 6, 196. [CrossRef]

27. Krištof, O.; Bulejko, P.; Svěrák, T. Experimental Study on Spray Breakup in Turbulent Atomization Using a Spiral Nozzle. Processes 2019, 7, 911. [CrossRef]

28. Ibrahim, M.; El-Naas, M.; Benamor, A.; Al-Sobhi, S.; Zhang, Z. Carbon Mineralization by Reaction with Steel-Making Waste: A Review. Processes 2019, 7, 115. [CrossRef]

(C) 2020 by the authors. Licensee MDPI, Basel, Switzerland. This article is an open access article distributed under the terms and conditions of the Creative Commons Attribution (CC BY) license (http://creativecommons.org/licenses/by/4.0/). 